Location of Logistics Companies:

\title{
A Stated Preference Study to Disentangle the Impact of Accessibility
}

\author{
Ann Verhetsel ${ }^{1}$, Roselinde Kessels ${ }^{2}$, Peter Goos ${ }^{2 \cdot 3}$, Toon Zijlstra ${ }^{1}$, Nele Blomme ${ }^{1}$, Jeroen Cant \\ ${ }^{1}$ University of Antwerp, Faculty of Applied Economics, \\ Department of Transport and Regional Economics \\ Prinsstraat 13, B-2000 Antwerpen, Belgium \\ ann.verhetsel@uantwerpen.be
}

\section{${ }^{2}$ University of Antwerp, Faculty of Applied Economics, Department of Engineering Management \& StatUa Center for Statistics, Prinsstraat 13, B-2000 Antwerpen, Belgium}

${ }^{3}$ Erasmus Universiteit Rotterdam, Erasmus School of Economics, Department of Econometrics, Postbus 1738, 3000 DR Rotterdam, the Netherlands 


\title{
Location of Logistics Companies:
}

\section{A Stated Preference Study to Disentangle the Impact of Accessibility}

\begin{abstract}
Due to the globalization and the fragmentation of industrial production processes, the logistics sector, organizing the linkages between different production plants and the market, is growing fast. This results in an increasing demand for suitable new business locations. Previous research has indicated that accessibility is a key factor in the location decision making process. Though the literature on this subject is extensive, little research has been done to quantify the impact of the different dimensions of accessibility on the location decision process of logistics companies. This paper aims to fill this void in the literature by means of a revealed preference study (using a Geographic Information System (GIS) analysis) and a stated preference study (using a designed discrete choice experiment) in Flanders (Belgium). The results of the revealed preference study served as input to the design of the choice situations in the stated preference study. In the stated preference study, the respondents were confronted with a series of choice situations described by means of accessibility variables as well as land rent information. An analysis of the resulting data by means of discrete choice modeling revealed that land rent is the most important factor in the location choice of logistics companies in Flanders. Access to a port is the second most important factor, followed by access to a motorway, the location in a business park and an inland navigation terminal, which are all about equally important. Access to a rail terminal plays no significant role in the location choice of logistics companies in Flanders.
\end{abstract}

Keywords: logistics, accessibility, transport geography, discrete choice modeling, Belgium 


\section{Introduction}

In recent years, globalization has resulted in an increasing spatial division of production and consumption, and an ongoing fragmentation of production. This evolution entails a major growth in the demand for logistics. One key decision in the planning process of the logistics operations is the decision where to locate these activities. This paper aims to provide new insights into the driving factors of location decision and to quantify the relative importance of the different characteristics of potential locations for logistics companies. Logistics is very important for the economy of the European Union, as demonstrated by the words of the European Union's Commissioner for transport Siim Kallas (2012): "Freight transport and the accompanying logistics industry represent one of the most dynamic and important sectors of the European economy, accounting for at least 10\% of GDP." The local importance of logistics should also not be underestimated. According to the National Bank of Belgium logistics created $7.9 \%$ of Belgium's GDP and $8 \%$ of domestic employment in 2005 (Lagneaux, 2008).

Logistics companies act as intermediaries that connect all stages of the international supply chain. The heterogeneity of logistics firms, however, makes that neither a consistent nor a standardized notion of logistics exists. On its homepage, the Council of Supply Chain Management Professionals (CSCMP, 2014) uses the following comprehensive definition: "Logistics is that part of the supply chain that plans, implements, and controls the efficient, effective forward and reverse flow and storage of goods, services and related information between the point-of-origin and the point-of-consumption in order to meet customers' requirements." For the purpose of this study, we solely focus on logistics plants dealing with material flows of goods between separate locations and the related storage activities. The reason for this is that logistics plants engaged in these activities require large amounts of land. Logistics providers focusing mainly on services will instead often opt for standard real estate such as office blocks.

Despite the general economic climate, the logistics real estate market appears to remain an important factor of growth. Many global leading logistics groups have a presence in Belgium. Flanders in particular seems to be an attraction pole because of its seaports and its important links to the European hinterland. Within Flanders, the Antwerp region is by far the most important location for logistics activities. Further, the axis between Antwerp and Brussels is also a preferred location for many logistics companies. The Flemish government has therefore initiated a process to make Flanders one of the main smart hubs of Europe in terms of sustainable logistics by 2020 (Flemish Government, 2012). This endeavor inspired us to study the location choice decisions of logistics companies in Flanders. The case study of Flanders may be useful for other regions that are interested in raising the number of logistics locations.

The location choice decision is a function of the locations' many different characteristics, such as the proximity to ports, highways and railroads, and the cost. A method suitable to quantify the importance of each of these dimensions and to acquire insight into the trade-offs made between the different dimensions is the stated preference method, also known discrete choice method (Hensher et al., 2005). Instead of asking respondents directly which attribute they find most important, the discrete choice method combines several attributes in one location profile in order to create a more realistic context. As in Bolis and Maggi (2003), one of the key outputs of the stated preference study we present in this paper is the Willingness to Pay for certain characteristics of a location. In the choice of locations for logistics businesses, however, the use of stated preference studies is rather uncommon. According to Hall et al. (2006), there is a need for more empirical research on this topic. When conducting a stated preference study, two important challenges are (i) to decide on the attributes of the choice alternatives 
and the levels of these attributes, and (ii) to determine the exact choice tasks to be performed by the respondents. To determine the attributes and the attribute levels in our study, we built on revealed preferences of logistics companies. To decide on the exact choice tasks, we utilized the optimal experimental design approach advocated by Bliemer and Rose (2010) and Kessels et al. (2009, 2011bc).

The remainder of this paper is organized as follows. In Section 2, we provide a review of the literature on the location decision process of logistics companies. In Section 3, we discuss the stated choice approach in detail. We pay attention to the choice model as well as to the design of the questionnaire and the computation of the Willingness to Pay. A major step in the design of the study was a preparatory GIS exercise to identify the actual accessibility characteristics of existing logistics sites in Flanders. In Section 4, we discuss the results of our stated choice exercise. Finally, in Section 5, we come to a conclusion and articulate some policy recommendations.

\section{On logistics companies, accessibility and location decision making}

The logistics firms under study, namely those that deal with material flows of goods between separate locations and the related storage activities, require large amounts of land. In that, their geography is close to that of most industrial companies. Therefore, to shed light on the theory of logistics firms' decision making, it is useful to draw upon the long history of conceptual and empirical research on industrial firm locational decision making within the field of economic geography. Research on the location of logistics companies is hitherto somewhat underdeveloped, in spite of its growing importance in the global economy. Few publications focus on the locational patterns of logistics on a macro scale (Hesse and Rodrigue, 2004), but little is known on the location decision process.

From the 1970s on, the behavioral approach became quite popular in studies dealing with the location decision process of economic activities. This research line stresses the subjective dimension in the location decision making process, hereby reacting on the 'homo economicus' assumption of the (neo)classical location theories. The behavioral approach resulted in a multitude of papers based on extensive surveys and in-depth interviews and describing the importance of different variables in the location decision process either using simple frequency statistics or using a narrative style. This resulted in severe criticism of both the (neo)classical approach and the emerging structuralist schools. A major criticism was that no generally accepted methodology was available, which resulted in a lack of strong empirical regularities and generalizations in behavior. Consequently, the behavioral approach did hitherto not contribute substantially to the development of theory explaining economic location (Healey and Ilbery, 1990).

The introduction and development of the stated preference method, also known as the discrete choice method, allows us to lift the behavioral approach to a much higher level. The location choice decision is a function of the locations' many different characteristics. A method suitable to quantify the importance of each of these dimensions and to acquire insight into the trade-offs made between the different dimensions is the stated preference method (Hensher et al., 2005). The use of stated preference studies is nowadays common in transportation (modal choice) and marketing, and increasingly also in health economics and environmental economics. In the choice of locations for economic activities like logistics businesses, however, the use of stated preference studies is so far uncommon.

Hayashi et al. (1986) applied an early discrete choice model to study the impact of accessibility (defined here as the distance in kilometers to the nearest motorway junction), and transport and land use policies on location preference of industrial companies in Japan. Accessibility came out as the 
most important factor in the location decision process of industrial companies. In contrast with Hayashi et al. (1986), we focus on logistics companies and we utilize different levels of the attributes in our stated preference study. The use of attributes with multiple levels in stated preference studies gained popularity since Hensher et al. (1988) pointed out the usefulness of stated preference methods in transportation research after many years of almost exclusively using revealed preference methods. Leitham et al. (2000) applied a discrete choice model for the location choice of industrial organizations in Scotland, $12 \%$ of which were specialized in distribution. We have to jump in time to Willigers and van Wee (2011) to find a more recent stated preference study on accessibility and location of companies. The study is, nevertheless, limited in scope as only rail accessibility of different types of firms is taken into account.

In our study, we focused on Flanders, the northern part of Belgium situated just south of the Netherlands. In Flanders, there has been a substantial amount of locally disseminated qualitative research based on classic interviews or surveys within companies aimed at identifying the factors that drive the location decisions of logistics companies (Bus et al., 1999; Idea Consult, 2001; Reijs et al., 2001; IBM, 2004; BCI et al., 2007, 2008; Cabus et al., 2008). According to these studies, the most important factors appear to be accessibility, infrastructure, the availability and cost of land, and labor and market proximity. By far the most important factor is accessibility by road. The increasing importance of multimodal accessibility is often offset by cost, especially for smaller logistics companies. Trade-offs need to be made between the availability of multimodal transport infrastructure and the cost of the location. With this article, we follow up on the qualitative research performed concerning the Flemish logistics sector, and quantify the trade-offs made by key players in their location decision. When conducting a stated preference study, one has to decide on the attributes of the choice alternatives. We decided to include various dimensions of accessibility, land rent and whether or not a site location is in a business park.

Whatever the approach for studying location decision making of economic activities, accessibility turns out to be a major decision factor, either expressed by means of a distance or a transportation cost or with more complex measurements of accessibility. As for logistics companies the focus of the industry is transporting goods itself, accessibility is the central location factor (Hesse and Rodrigue, 2004). Logistic activities need to be located centrally in networks in order to be able to receive and deliver goods in a (cost) efficient way. As transportation by road is the main mode for haulage (in EU $75 \%$, in Flanders $81 \%$ of the modal split for freight transport), the accessibility of a site location by road is expected to be of utmost importance in the decision process (European Commission, 2014; Steunpunt Goederen- en personenvervoer, 2013). Indeed, transportation by road provides a large flexibility and complete independence of special infrastructures. However, the call for more sustainable transport of goods at the beginning of this millennium and the growing congestion on highways have resulted in an increased consideration of alternative modes, like inland waterways and rail, by logistics firms. As a consequence, when evaluating site locations, the access to terminals along inland waterways and rail infrastructure may have gained importance. Finally, as most logistics companies act in a global world with a growing fragmentation of production, transportation over long distances is important. Accordingly, access to maritime transportation and thus port infrastructure is important as well (Hong, 2007a-b;Hong and Chin, 2007; Lu and Yang, 2006).

Next to accessibility, the cost of land is a major location factor, certainly for logistics firms (Hesse, 2004; Holguín-Veras et al., 2005; Nguyen and Sano, 2010; Ozmen-Ertekin et al., 2007). Especially in highly urbanized areas like Flanders, extensive surfaces of land are scarce and the competition between different kinds of land use is substantial. Industrial and logistic companies can only afford land rents that are far smaller compared to what housing, office and retail projects can pay. This may 
push logistics firms to more peripheral, less accessible, locations. Clearly, a trade-off between cost of land and accessibility is thus required in the location decision process.

In Flanders, as elsewhere in Europe, there is a long tradition of providing land for economic activities by the government. In addition to modest land rents and investments in accessibility, the government provides certainty of concessions located in business parks. Moreover, we expect firms located in such parks to benefit from agglomeration advantages coming from joint utilities and close customer/supplier relations. As the Flemish government invests a lot in business parks to attract new businesses, an evaluation of this measure is highly topical. For this reason, we include this location characteristic in our study.

We assume that the location decision process of logistics firms will differ depending on further characteristics of the company. To deal with this kind of heterogeneity, we include the size of the firm, the current transport modes used, and the type of packaging in our analysis. The location decision of large companies that are in need of extensive surfaces differs from the decision process of small companies. The latter are often located in geographical proximity to the residence of the companies' owners, so that the location of small companies is historically determined. However, due to problems they cause in their immediate environment (e.g., noise, traffic congestion), more and more of these small logistics companies have to consider a new location. Large companies usually have a more professional approach to location/relocations problems, and evaluate different location factors more rationally. Therefore, for large companies, more important changes can be expected. As large firms probably offer a larger number of services to a larger market, they are in need of higher levels of multimodal accessibility. The land rent most likely plays a more important role in the decision process of smaller companies, as their financial capability is relatively limited. Moreover, large companies offer local governments considerable income and a large number of jobs, as a result of which they are able to negotiate good locations on business parks for a relatively low price. The location decision process of logistics firms currently only using road transport will differ from those firms already using multimodal transport. The latter companies will value a higher multimodal accessibility more than the former, and probably have a stronger preference for a location in a business park to benefit from possible agglomeration effects. Logistics firms offering container transport are generally more globally oriented, so that they can be expected to value port infrastructure and multimodal accessibility higher than firms that do not deal with container transport. Transport by pallets is mainly done by road, so that road accessibility will be valued higher by companies specializing in that kind of transport.

In our discrete choice experiment, we want to quantify the trade-offs made by logistics companies in Flanders when choosing a location. To this end, the following hypotheses will be investigated:

- For logistics companies, the transportation of goods is at the core of their business, so accessibility plays a major role in the location decision.

- As transportation by road is far more important than other modes of transport, road accessibility is considered more important than the accessibility of rail, inland water and port terminals.

- Because central locations with an excellent accessibility will be more expensive than peripheral locations, logistics firms have to make a trade-off between the land rent and the accessibility.

- Governments offer attractive locations in business parks, combining accessibility, an attractive land rent, easy permits for operations and agglomerations effects. These locations are attractive for logistics firms in need of extensive lots of land. 
- Depending on individual logistics firms' characteristics, like size, currently used transport modes and type of packaging, the trade-off between different kinds of accessibility, the cost of land and the attractiveness of business parks will vary.

In order to design an appropriate choice experiment, we had to decide on the levels of the attributes included in the study. In the next section, a GIS exercise exploring the actual levels of accessibility and land rent in Flanders, is performed to choose adequate attribute levels. The design of the choice experiment and the statistical modeling are discussed as well.

\section{Setup of the stated choice experiment}

We used a stated choice experiment to quantify the trade-offs managers of logistics companies make in choosing between alternative site locations. In our stated choice experiment, we presented respondents with several choice situations involving two alternative site locations. In each choice situation, respondents had to indicate the alternative they preferred. The alternative site locations in a choice situation are described by levels of various attributes. We chose the attributes and attribute levels to be as realistic as possible. In this section, we describe the setup of our stated choice experiment. First, we list the attributes used and present the revealed preference study to identify appropriate levels for the attributes in our stated choice experiment. Next, we explain the experimental design of the study, the complete questionnaire presented, and the selection of the respondents. Finally, we describe the model used for the data analysis and the estimation of the Willingness to Pay (WTP).

\subsection{Selection of the attribute levels using a revealed preference study}

In our stated choice experiment, we included four accessibility attributes: 'road access', 'rail access', 'inland navigation access' and 'port access'. In addition, we included 'land rent' as a cost attribute. A sixth attribute we included in our experiment indicates whether or not a site location is in a business park. In the stated choice experiment, the respondents were forced to make trade-offs between the six attributes. This allows us to identify the attributes that matter most in the location decision process of logistics companies. Moreover, because we included a cost attribute in the experiment, respondents were forced to weigh cost against the other attributes, enabling us to calculate logistics managers' Willingness to Pay (WTP) for an improvement in site location.

Following Earnhart (2001), to present respondents with realistic alternative site locations in the stated choice experiment, we performed a revealed preference study to select appropriate levels for the four accessibility attributes 'road', 'rail', 'inland navigation' and 'port', and the attribute 'land rent'. We selected the levels of the accessibility attributes using a GIS (Geographic Information System) analysis that returned actual distances from Flemish logistics sites to motorway junctions, rail and inland navigation terminals and ports. We selected the levels of the attribute 'land rent' by consulting the literature on Flemish real estate for logistics companies.

Using the actual distances from Flemish logistics sites to various transport infrastructures is a very simple measure for accessibility. Throughout the last decade, many researchers (see, e.g., Geurs and van Wee, 2004; Lim and Thill, 2008; Thill and Lim, 2010) have developed better accessibility measures. We preferred, however, levels of accessibility that respondents in a stated choice experiment can easily understand and interpret. Many authors, including Birkin et al. (2002), Janssen and Uran (2003), Uran and Janssen (2003), Geurs and van Wee (2004), Vonk et al. (2005) and te Brömmelstroet $(2010,2012)$ follow the same reasoning and argue that easily understandable measures 
of accessibility or land use in surveys have a positive impact on understanding, interpretation and communicability.

For the GIS analysis of the revealed preference data, we used the top 200 logistics companies in Flanders in terms of added value, as identified by the National Bank of Belgium. This may seem only a small portion of the almost 11,000 logistics companies active in Flanders, but the vast majority of these companies are (very) small SMEs, including independent truckers (Lagneaux, 2008). Hence, by selecting the top 200 logistics companies, only firms with considerable land use and accessibility needs were included. This small number of companies seems to have a substantial influence on the take-up of logistics space (Jones Lang Lasalle, 2012a-b, 2013). From the selected companies, we considered only the sites that generate commodity flows, i.e. sites that deliver services such as freight rail transport, freight road transport, freight transport by sea and coastal waters, freight transport on inland waterways, courier services (excluding the national postal services) and storage. This resulted in a representative sample of 235 large logistics sites (one firm may have different sites). Included in the sample are sites of leading international logistics providers such as FedEx, UPS, Caterpillar, Cargill, Vanguard, Brink's, NYK, P\&O, MSC, Kuhne+Nagel, Dentressangle, Salvesen, TNT, DHL, PSA and Katoennatie.

Thomas et al. (2003) showed that there are no major differences between topological accessibility in Belgium expressed in terms of transportation costs and in terms of distances. We therefore started the GIS analysis by geocoding the 235 sites in ArcGIS 10 and calculated driving distances to the transport infrastructures via the shortest route method using the spatial analyst extension. The locations of the selected sites and the different transport infrastructures under study are shown in Map 1.

Map 1: Site locations of the top 200 logistics companies (in terms of added value) in Flanders and available transportation infrastructures.

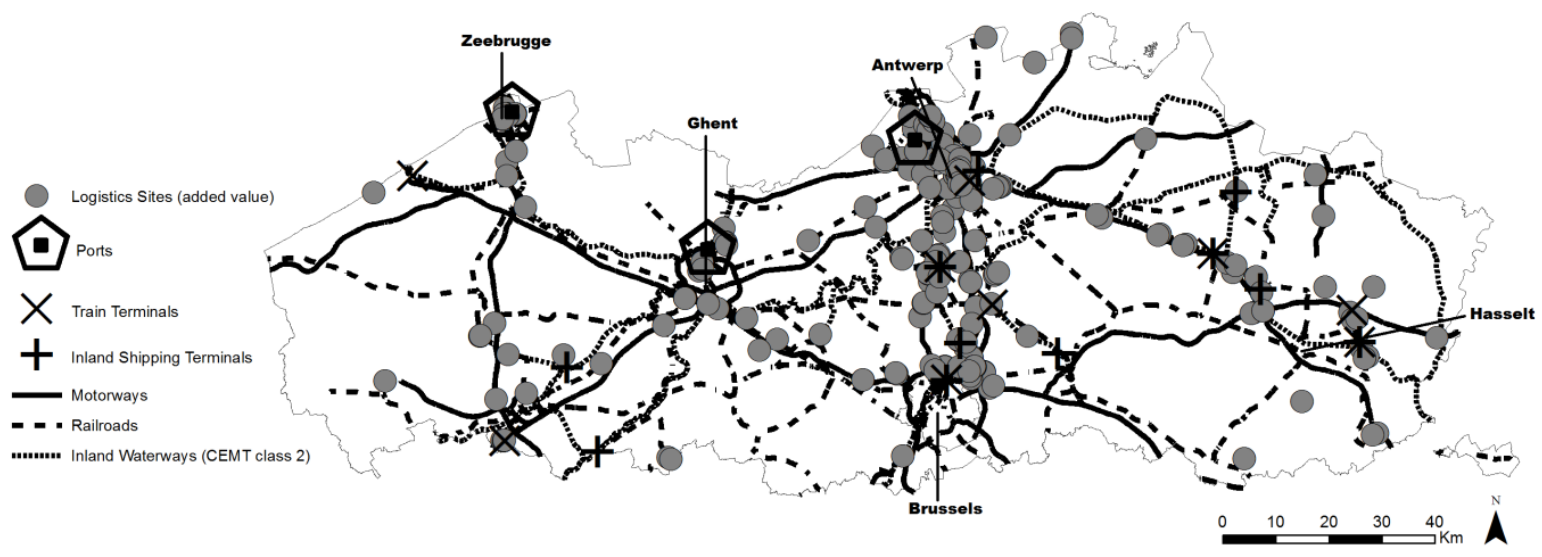


First, as a measure for 'road accessibility', we calculated the distances between the 235 logistics sites and the nearest motorway junctions in time units (minutes). The average distance to the nearest motorway junction for the 235 logistics sites is 2.7 minutes. Figure 1 shows the distribution of the distances to the nearest motorway junction. The distribution reflects the high density of the Flemish motorway network (Thomas and Verhetsel, 1999). The majority of the sites are located within six minutes of a motorway junction. The bold vertical lines in the figure indicate the four levels we selected for the attribute 'road accessibility': 2, 5, 10 and 15 minutes. We selected these four levels because they cover the entire range of distances well.

Figure 1: Distances in minutes to a motorway junction of 235 main logistics sites in Flanders.

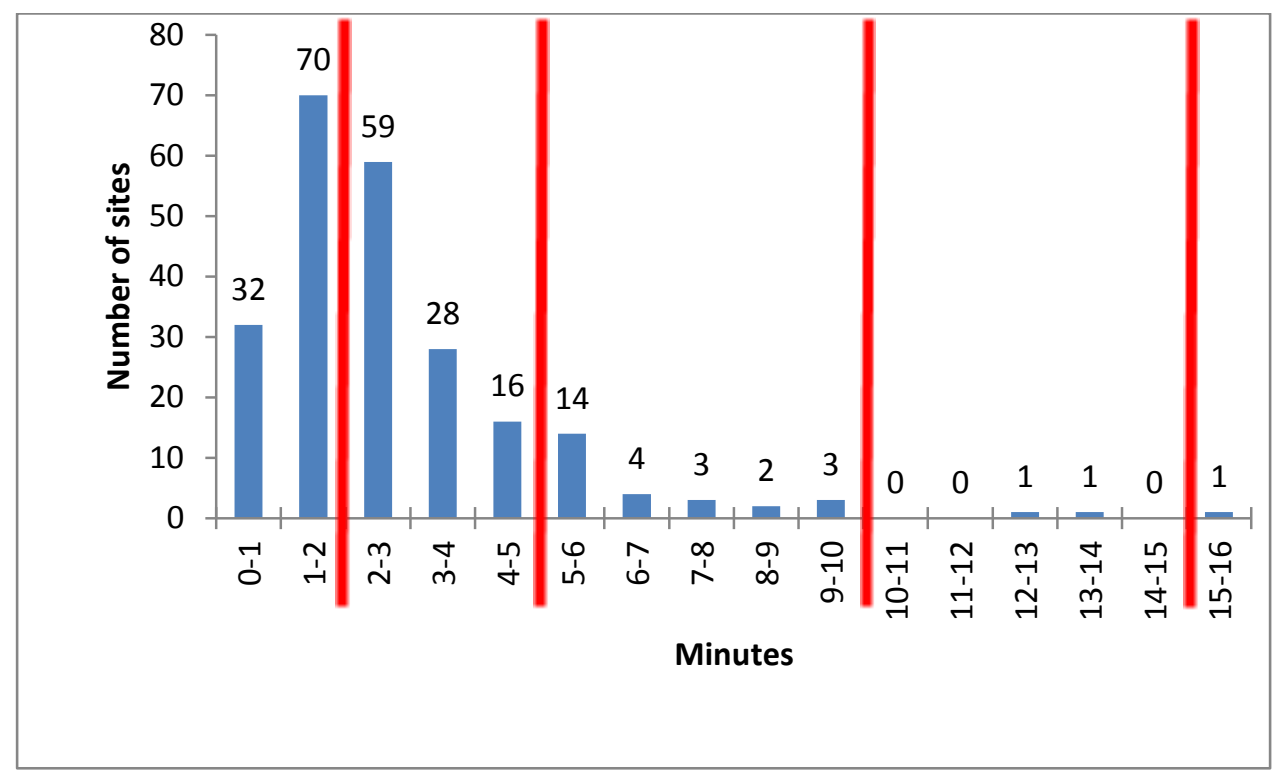

Second, as a measure for 'rail accessibility', we calculated the distances in kilometers between the 235 logistics sites and the nearest rail (or trimodal) terminal on the basis of the road network. On average, the 235 sites are located at 8.6 kilometers from a rail connection where they have the ability to load and unload goods. Figure 2 shows the distribution of the distances in kilometers to the nearest terminal. Most sites are located within 10 kilometers of a rail (or trimodal) terminal. This is relatively close, but it does not necessarily imply that the companies take advantage of this proximity. The bold vertical lines in the figure define the four selected levels for the attribute 'rail accessibility': 0, 5, 15 and 30 kilometers. The first level of 0 kilometers means that the site itself has a rail (or trimodal) terminal and hence does not need other transport modes to reach it.

Third, we defined 'inland navigation accessibility' as the distance in kilometers between an inland navigation (or trimodal) terminal and a logistics site. On average, the 235 logistics sites are located at 7.4 kilometers from an inland navigation terminal. Figure 3 shows the distribution of the distances in kilometers to the nearest terminal. This distribution is quite similar to the one in Figure 2 for rail accessibility. Therefore, we selected the same levels for the attribute 'inland navigation accessibility' as for the attribute 'rail accessibility', i.e. 0, 5, 15 and 30 kilometers. 
Figure 2: Distances in kilometers to a rail (or trimodal) terminal of 235 main logistics sites in

2 Flanders.

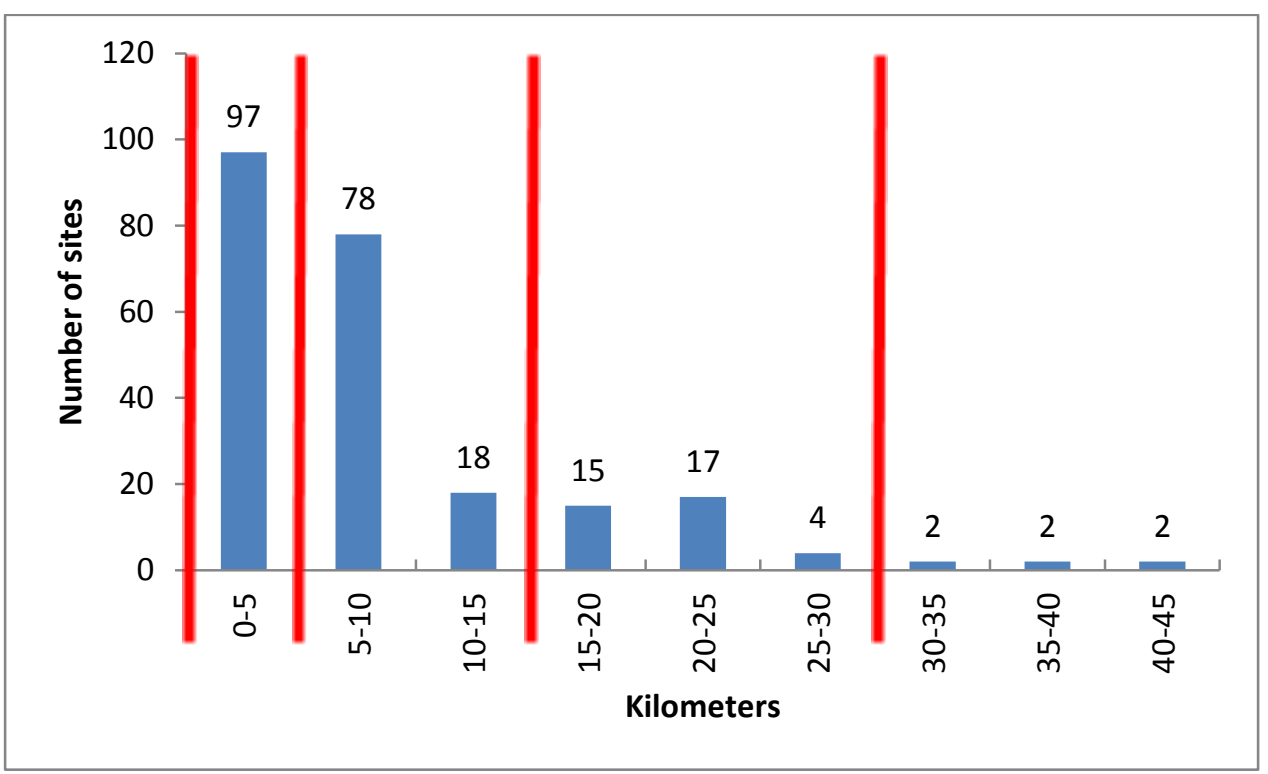

4

Figure 3: Distances in kilometers to an inland navigation (or trimodal) terminal of 235 main logistics sites in Flanders.

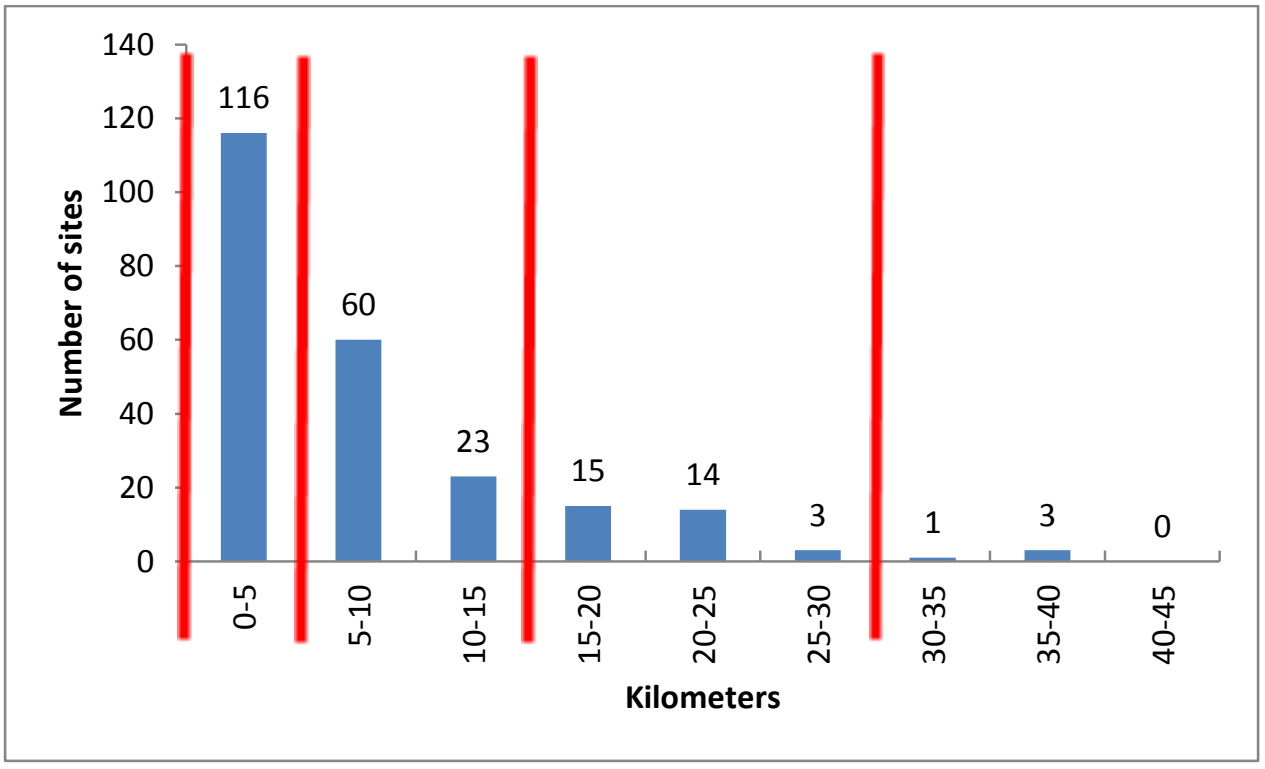

Fourth, as a measure for 'port accessibility', we calculated the distance to a seaport as the distance in kilometers of a logistics site to a central point in the nearest Flemish seaport. This analysis took into account the ports of Antwerpen (Antwerp), Gent (Ghent) and Zeebrugge (port of Bruges). The average distance of 34.6 kilometers to a port is substantially higher than the average distances to any of the other transport infrastructures. As a result, Figure 4, which contains the distribution of the distances in kilometers to a port, shows a different pattern than Figures 1,2 and 3. To cover the range of distances to a seaport for most of the logistics sites, we selected the levels 0, 10, 20 and 50 kilometers for the attribute 'port accessibility'. 
Figure 4: Distances in kilometers to a port of 235 main logistics sites in Flanders.

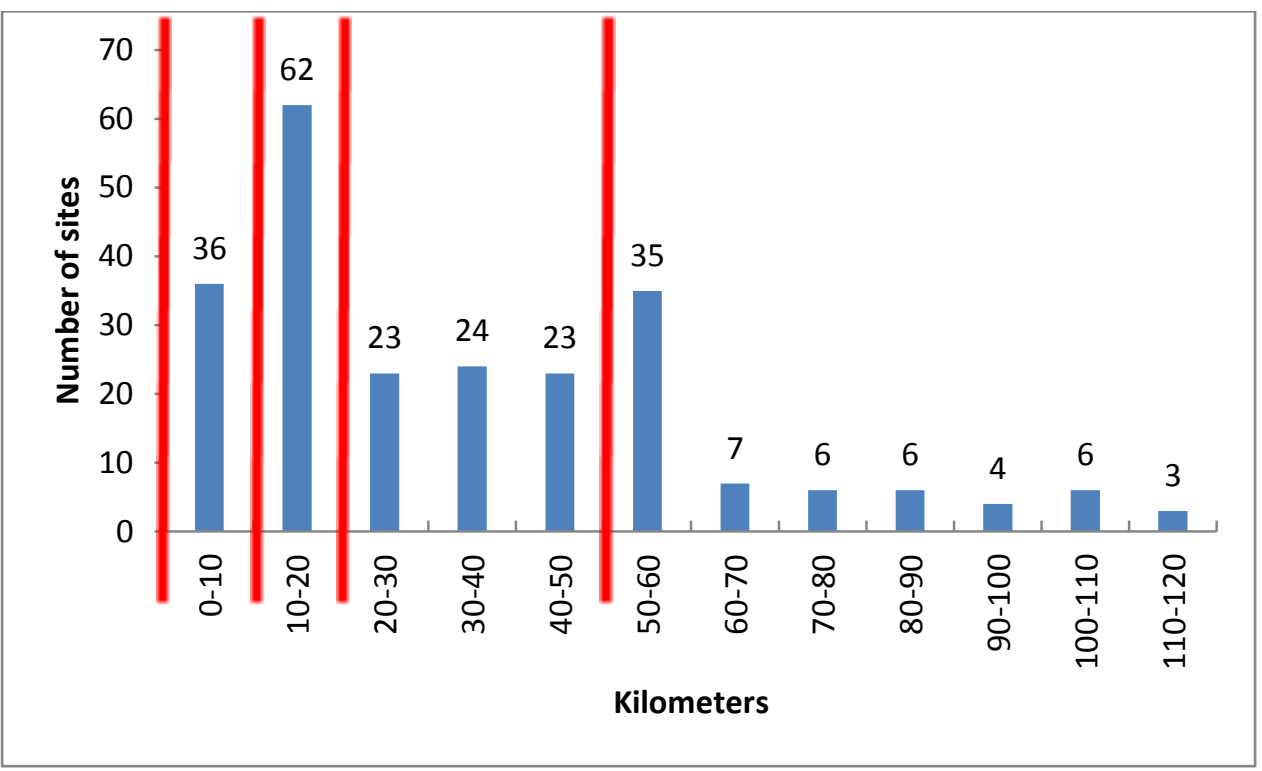

Finally, as a last step in our revealed preference study, we identified five suitable levels for the attribute 'land rent'. Little information regarding the latter is available from scientific or administrative sources. We thus had to rely on publications of the main players in the Flemish real estate market for logistics companies. The land rent estimates of these companies are quite similar. The land rent deviations seem to be realistic and reflect the differences in accessibility between them (Thomas et al., 2003). To cover a wide range of possible land rents, we selected $10 \mathrm{EUR} / \mathrm{m}^{2} /$ year, $35 \mathrm{EUR} / \mathrm{m}^{2} /$ year, 50 EUR/m²/year, $65 \mathrm{EUR} / \mathrm{m}^{2} /$ year and $90 \mathrm{EUR} / \mathrm{m}^{2} /$ year as the levels for the attribute 'land rent' in the stated choice experiment. The highest level, $90 \mathrm{EUR} / \mathrm{m}^{2} / \mathrm{year}$, then represents the high land rents in the top logistics regions in the neighboring countries (e.g. Amsterdam, Frankfurt, Munich, Paris and London). The one but highest level, $65 \mathrm{EUR} / \mathrm{m}^{2} /$ year, represents the land rent for the best logistics real estate possible in Belgium, $50 \mathrm{EUR} / \mathrm{m}^{2} /$ year is the average land rent for very good logistics locations, $35 \mathrm{EUR} / \mathrm{m}^{2} /$ year is the lowest observed land rent in the core logistics areas of Flanders, and 10 EUR $/ \mathrm{m}^{2} /$ year would be the land rent for an area which is very unattractive to logistics providers (CBRE, 2007; Cushman and Wakefield, 2010, 2011a-b-c-d; Jones Lang LaSalle, 2010).

The revealed preference study resulted in the selection of four levels for the four accessibility attributes and five levels for the attribute 'land rent'. Table 1 provides an overview of the six attributes in our study, including the attribute 'business park', and their levels.

Table 1: The six attributes and their levels in the stated choice experiment.

\begin{tabular}{llllll}
\hline Attribute & Level 1 & Level 2 & Level 3 & Level 4 & Level 5 \\
\hline Road & $2 \mathrm{~min}$ & $5 \mathrm{~min}$ & $10 \mathrm{~min}$ & $15 \mathrm{~min}$ & \\
Rail & $0 \mathrm{~km}$ & $5 \mathrm{~km}$ & $15 \mathrm{~km}$ & $30 \mathrm{~km}$ & \\
Inland navigation & $0 \mathrm{~km}$ & $5 \mathrm{~km}$ & $15 \mathrm{~km}$ & $30 \mathrm{~km}$ & \\
Port & $0 \mathrm{~km}$ & $10 \mathrm{~km}$ & $20 \mathrm{~km}$ & $50 \mathrm{~km}$ & \\
Land rent & $10 \mathrm{EUR}$ & $35 \mathrm{EUR}$ & $50 \mathrm{EUR}$ & $65 \mathrm{EUR}$ & $90 \mathrm{EUR}$ \\
Business park & Yes & No & & & \\
\hline
\end{tabular}




\subsection{Experiment design}

Our stated choice experiment presented each respondent with 20 choice situations involving two alternative site locations, called profiles. For each choice situation, respondents were asked to indicate the profile they preferred. The alternative site locations or profiles are combinations of levels of the attributes in Table 1. However, we included only four of the six attributes in each choice situation to limit the cognitive burden imposed on the respondents, reducing respondent fatigue toward the end of the experiment as well the likelihood that respondents will resort to undesirable choice behavior. The resulting profiles are called partial profiles (Green, 1974; Kessels et al., 2011a, 2012). Figure 5 shows an example of a choice situation where respondents had to choose between two site locations A and B, described by four of the six attributes.

Figure 5: Screenshot of a choice situation used in the stated choice experiment.

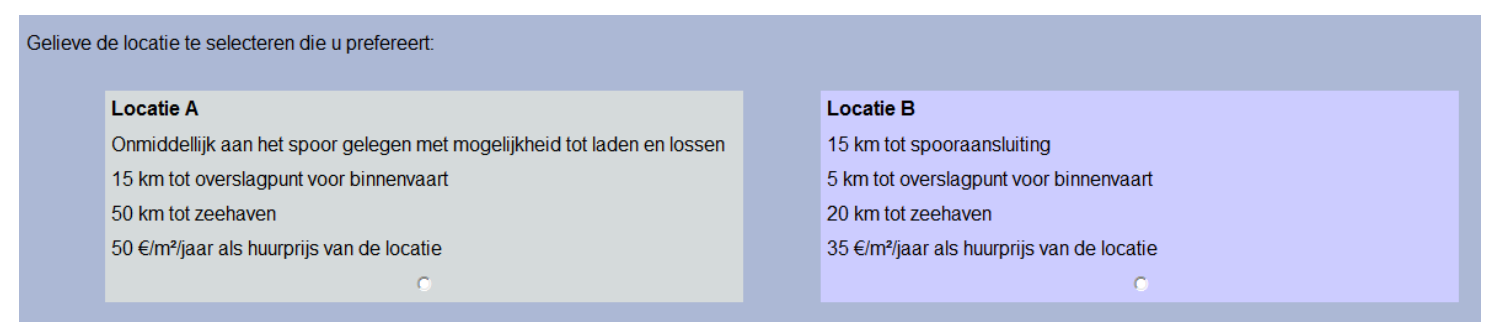

Example of a choice situation involving one alternative (Locatie A) which has immediate access to a rail terminal, is located at $15 \mathrm{~km}$ from an inland navigation terminal and at $50 \mathrm{~km}$ from a sea port, and has an annual cost of $50 \mathrm{EUR} / \mathrm{m}^{2} / \mathrm{year}$ and another alternative (Locatie B) located at $15 \mathrm{~km}$ from a rail terminal, at $5 \mathrm{~km}$ from an inland navigation terminal and at $20 \mathrm{~km}$ from a sea port, and has an annual cost of $35 \mathrm{EUR} / \mathrm{m}^{2} /$ year.

To maximize the information content of the stated choice experiment, we created two different surveys by constructing a partial profile design involving 40 choice situations and dividing it into two sets of 20 choice situations. We ensured that each survey was filled out an equal number of times. As pointed out by Sándor and Wedel (2005), using 40 instead of 20 different choice situations results in a larger amount of information on the respondents' preferences and therefore in more precise estimates of the relative importance of the attributes and attribute levels as well as better estimates of the Willingness to Pay. Each choice situation of the partial profile design varies the levels of four of the attributes. These varying attributes differ from choice situation to choice situation. We determined the varying attributes in every choice situation using the variance-balance partial profile design approach developed for attributes with differing numbers of levels (Kessels et al., 2012). Each of the two surveys varies the 2-level attribute 'business park' in 8 choice situations, each of the 4-level accessibility attributes in 14 choice situations and the 5-level attribute 'land rent' in 16 choice situations (Verhetsel et al., 2013).

The variance balance approach of Kessels et al. (2012) builds on the rich literature on Bayesian Doptimal or D-efficient stated choice designs, which are increasingly considered as state of the art (Rose and Bliemer, 2009; Bliemer and Rose, 2010; Kessels et al., 2011a-b-c, 2012). A key feature of the Bayesian D-optimal partial profile designs is that they take into account prior knowledge concerning the respondents' preferences. The usefulness of prior information when setting up stated choice experiments was first recognized by Huber and Zwerina (1996). For our experiment, we know that respondents prefer low land rents over high ones, and prefer to be closer to the motorway, a rail or an inland navigation terminal and a sea port. Additionally, we took into account expert information which led us to anticipate that the four accessibility attributes are potentially equally important to the population of logistics companies, and that the attribute land rent would most likely turn out to be the 
most important attribute. For the 2-level attribute business park, however, we did not obtain any prior information about respondents' preferences (Verhetsel et al., 2013). Appendix A provides detailed information on the design of the stated choice experiment.

For each respondent, the final questionnaire consisted of two parts. The first part contained general questions on the characteristics of the logistics plants, such as turnover, removals, logistics services offered on site, annually transported tonnage by mode and land rent. The first part of the questionnaire was identical for each respondent. The second part of the questionnaire contained the actual stated choice experiment, comprising one of the two different surveys we created. We distributed the two versions of the questionnaire online using Sawtooth's survey software SSI Web, version 8.1 (Sawtooth Software, Orem, UT, USA). The questionnaire language was Dutch. Respondents to the questionnaire were managers from logistics plants involved in location decisions. To obtain reliable results, our goal was to collect data from at least 100 managers. Initially, we only recruited respondents from the 235 sites studied in the GIS exercise, but because this was not sufficient to reach the desired number of 100 respondents, we eventually also contacted other, smaller, logistics firms.

\subsection{Statistical model}

We used two types of choice models to analyze the data from our stated choice experiment: multinomial logit (MNL) and mixed multinomial logit models (MMNL). The MNL is well-known and often used in choice modelling (Hensher et al., 2005). The MMNL gained increasing popularity in the last decade, mainly because it allows preference heterogeneity, by means of the introduction of random parameters in the model (Train, 2009; Croissant, 2013). The MMNL is therefore also known as the random parameter logit model. Our MMNL models use panel techniques based on 20 observations per respondent (Croissant, 2013).

To estimate the parameter vector we used a maximum likelihood estimation approach which maximizes the probability of obtaining the responses from the selected data sample (Hensher et al., 2005). In the MNL models we used the simple 'Newton-Ralphson' maximization method. For the MMNL models we used the more advanced 'Broyden-Fletcher-Goldfarb-Shanno' method (Henningsen and Toomet, 2011). We computed the overall significance and the relative importance of the six attributes by means of likelihood ratio (LR) tests and present the marginal utility values of the attribute levels.

An interesting feature of stated choice analysis is the possibility to calculate the Willingness to Pay (WTP) for an improvement with respect to one or more attributes (Hensher et al., 2005). For our study, this involves calculating how much managers of logistics plants are willing to pay for an improvement in site location. The condition for being able to calculate a WTP value is that at least one attribute is expressed in a monetary unit and modeled using linear coding. In our stated choice model, the attribute 'land rent' is expressed in EUR/ $\mathrm{m}^{2} /$ year.

In a follow-up analysis, we also modeled preference heterogeneity among the respondents using covariates. To this end, we included four covariates in the model, describing the characteristics of the respondents. This resulted in a model where the preferences were allowed to vary with the levels of the covariates. For every covariate the reference category is the majority of the sample. An advantage of this approach compared to the general panel mixed logit model is that it does not only capture respondent heterogeneity, but it also offers a possible explanation for it.

We carried out the entire data analysis using the 'mlogit' package (version 0.2-4) in the statistical software platform 'R' (R core team, 2013; Croissant, 2013). 


\section{Results}

2 We first describe the general characteristics of the logistics sites whose managers participated in the 3 stated choice experiment. Next, we present the results of the choice model estimation and the 4 corresponding WTP estimates.

\section{$5 \quad 4.1$ Respondent characteristics}

6 The first part of the online questionnaire was intended to collect information concerning the 100 7 respondents. This includes information on the surface area of the sites where the respondents are 8 employed, address information of the sites, transport activities offered on site, the way goods are actually transported, and whether the company has moved sites in the past five years or is considering doing so in the near future.

The average surface area of the sites is $15,000 \mathrm{~m}^{2}$, the median is $5,000 \mathrm{~m}^{2}$, and the largest site covers $340,000 \mathrm{~m}^{2}$. In terms of added value, there is a good spread of large, medium and small sized companies among the respondents. Large firms have an added value of more than 4,500,000 EUR, medium sized firms have an added value between 650,000 and 4,500,000 EUR and small firms have an added value of less than 650,000 EUR. Concerning the actual transport modes offered (which include also air transport), 56 respondents indicated they are only occupied with road transport. A total of 25 respondents use at least two transport modes, one of which may be road, and 19 of them offer at least three transport modes. In addition, 39 plants specialize in palletized goods, while 16 exclusively deal with containers and 14 transport both. The remaining 31 sites transport goods in another fashion, e.g. as parcel, general commodity or bulk.

Map 2 shows the site locations of the 100 respondents in combination with the different transport infrastructures under study. Most sites are clustered around the three major seaports and along the Antwerp-Brussels axis. A comparison of Map 2 with Map 1 shows that the spatial distribution of the companies in these maps is quite similar. In the last five years, 17 plants changed location. The reasons for this are as diverse as the need for a new premise and/or space for expansion, the need for a more profitable location, the need to be located closer to home, the need to avoid high land rent and a takeover. Another ten plants indicated they were planning to move within the next five years. The most important reasons mentioned for this are expansion and/or restructuring plans. The fact that $27 \%$ of the respondents in our survey have recently moved sites or expressed the desire to do so, shows that our stated choice study is timely and relevant. 
Map 2: Site locations of the 100 respondents in the stated choice experiment in Flanders and available

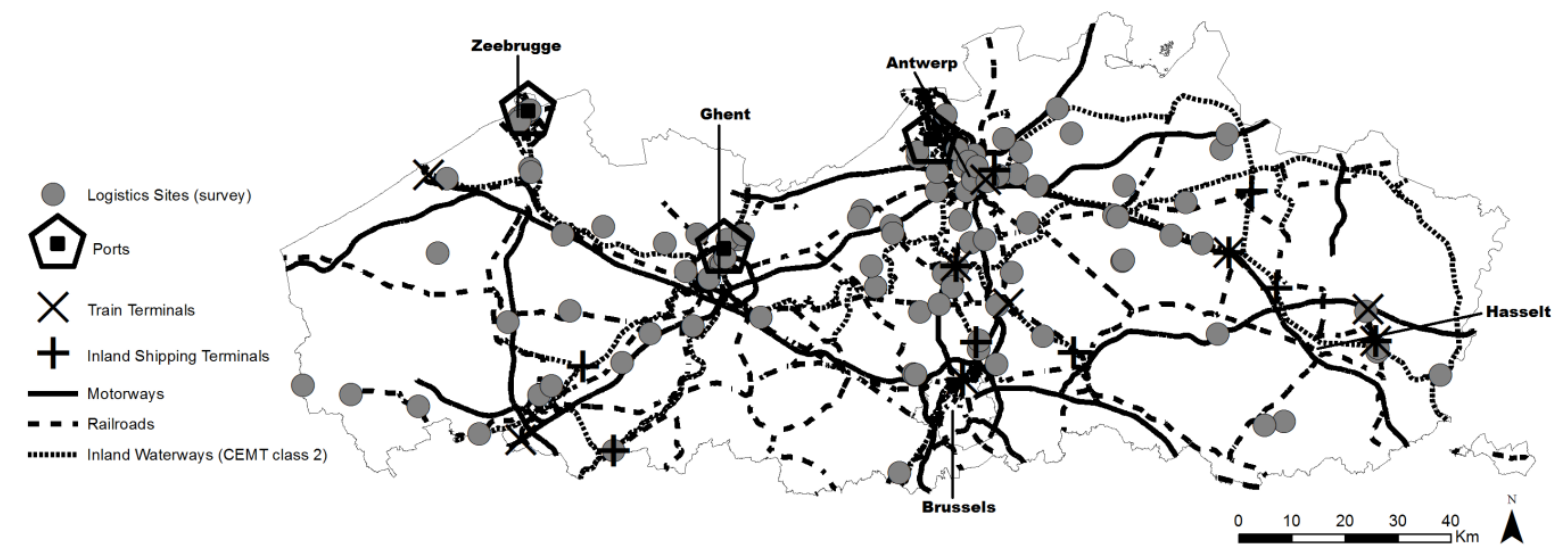

3

\subsection{Modeling results}

First, we generated and compared the results of four basic models. We estimated a linear and a partworth MNL and a linear and a part-worth mixed multinomial logit (MMNL) model, using panel techniques. All these initial models include all six attributes used in the stated choice experiment. In the initial MMNL model all six attributes are considered to be random parameters with a normal distribution. To estimate the mixed models with reliable likelihood figures we used 7,500 quasirandom Halton draws. The categorical models enable to capture possible nonlinear relationships between the utility of an alternative site location and the attribute levels. We selected the best performing model from the four initial models based on the log-likelihood. Next, we checked the assumed distribution for the random parameters and we introduced covariates in the model to study the preference heterogeneity among the logistics' companies in detail, taking into account their most important characteristics. Finally, our model is simplified by retaining only significant attributes, random parameters and interactions. We call the resulting model the final model.

The MMNL model with linear coding provides the best model fit and the highest pseudo $\rho^{2}$ of the four initial models. Introducing random parameters into the model improves the model significantly, with respect to the MNL models. All random parameters are significant and show considerable and significant standard deviations, meaning that there is a certain level of preference heterogeneity among the respondents. Consequently, there is no reason to transform some of these random parameters into standard fixed parameters, though in some cases the results might suggest that the assumption of a normal distributed random variable is incorrect, since these include positive and negative values. Examination of the true distribution of the random parameters is beyond the scope of our purposes 
here. The linear MMNL has a log-likelihood closer to zero, though the difference with the part-worth MMNL model is modest and not significant. Because simple models are preferable to more complex models, we use the linear model.

Table 2 shows the marginal utility values of the attribute levels and the significances of the attributes' effects obtained from likelihood ratio (LR) tests for the linear MMNL model, the best of the initial models. The LR tests and t-values indicate that all attributes are significant at the 0.01 level except for the estimated mean of rail accessibility. In other words, we did not find evidence to support that rail access affects the location choice for the majority of the respondents. The standard deviation of rail access is small, but significant, we consider this to be noise. Hence, we dropped the attribute 'rail access' from the model. Our findings are in line with research presented by Hilmola (2007), Nash and Rivera-Trujillo (2007) and Vassallo and Fagan (2007), who reported that freight rail transport in Europe is inefficient due to the prioritization of passenger transport, a lack of interoperability of the different national rail networks, poor service quality, high rates, and a lack of government incentives. Deville and Verduyn (2012) confirm these results for Belgium. This negative image of freight rail services for most logistic companies is thus reflected in the results of our stated choice experiment.

The six attributes in Table 2 are ranked in order of importance, where the importance of an attribute is measured by $-\log 10$ (p-value of the LR test). Figure 6 shows the importance of the different attributes relative to the importance of the attribute 'land rent', which is the most important attribute. The attribute 'port accessibility' ranks second, followed by 'business park', 'road accessibility' and 'inland navigation accessibility', which are all about equally important. This is also consistent with the results of the MNL model. The location for logistics plants is thus primarily determined by the cost of the available sites. Of course, all other things being equal, the lower the costs, the more attractive a location. At first sight, the superior importance of land rent over accessibility may be surprising. However, an extensive body of literature on the impact of land rent on location supports this finding. Moreover, we divided accessibility in four different attributes, one for each mode. The result that 'port accessibility' is the most important accessibility attribute is also in line with the existing literature and does not come as a surprise since there are three seaports in Flanders which generate a large demand for transport. Somewhat surprising though is that the attributes 'business park' and 'road accessibility' are about as important as 'inland navigation accessibility'. This is in contrast with the findings in the local literature, which stresses the importance of road accessibility. We therefore expected the attribute 'road accessibility' to play a more prominent role. A possible explanation for the lower relative importance of road accessibility is the high density of motorways and motorway junctions in Flanders, i.e. one never has to drive far to access a motorway (Thomas and Verhetsel, 1999). In most cases, the journey from a logistics site to a motorway constitutes only a very small fraction of the total journey. 
Table 2: Model results for the linear MNL and the linear MMNL model

MNL model

MMNL model

\begin{tabular}{lrrrrrrr}
\hline Attribute & \multicolumn{1}{l}{ est. } & \multicolumn{1}{l}{ t-value } & \multicolumn{1}{l}{ est. } & \multicolumn{1}{c}{-value } & \multicolumn{1}{l}{ s.d. } & t-value & LR effect $\left(\chi^{2}\right)$ \\
\hline Land rent $[€]$ & $\mathbf{- 0 . 0 3 6}$ & -19.43 & $\mathbf{- 0 . 0 7 3}$ & -14.67 & $\mathbf{0 . 0 5 2}$ & 10.67 & $\mathbf{6 8 4 . 1}$ \\
Port [km] & $\mathbf{- 0 . 0 3 0}$ & -10.98 & $\mathbf{- 0 . 0 5 1}$ & -9.81 & $\mathbf{0 . 0 4 8}$ & 7.22 & $\mathbf{2 3 0 . 6}$ \\
Business Park [yes] & $\mathbf{0 . 3 7 8}$ & 8.56 & $\mathbf{0 . 6 2 9}$ & 7.86 & $\mathbf{0 . 8 2 5}$ & 7.60 & $\mathbf{1 4 3 . 1}$ \\
Road [min] & $\mathbf{- 0 . 0 8 8}$ & -8.71 & $\mathbf{- 0 . 1 6 0}$ & -8.74 & $\mathbf{0 . 1 3 9}$ & 6.15 & $\mathbf{1 3 3 . 6}$ \\
Inland nav. [km] & $\mathbf{- 0 . 0 3 1}$ & -7.40 & $\mathbf{- 0 . 0 5 0}$ & -7.05 & $\mathbf{0 . 0 4 9}$ & 4.82 & $\mathbf{1 0 9 . 4}$ \\
Rail [km] & 0.000 & 0.10 & -0.003 & -0.54 & $\mathbf{0 . 0 3 2}$ & 2.97 & $\mathbf{4 2 . 5}$ \\
\hline
\end{tabular}

Model overview

Number of parameters

6

Final log-likelihood

$-1060.8$

$\mathbf{- 9 0 0 . 6}$

Zero log-likelihood

$-1386.3$

$-1386.3$

McFadden $\rho^{2}$ (adj.)

0.235

$(0.230)$

$0.350 \quad(0.342)$

Note: Bold figures are significant on the 0.01 level

3

Figure 6: Importance of the six attributes in the initial MMNL model relative to the most important attribute 'land rent'.

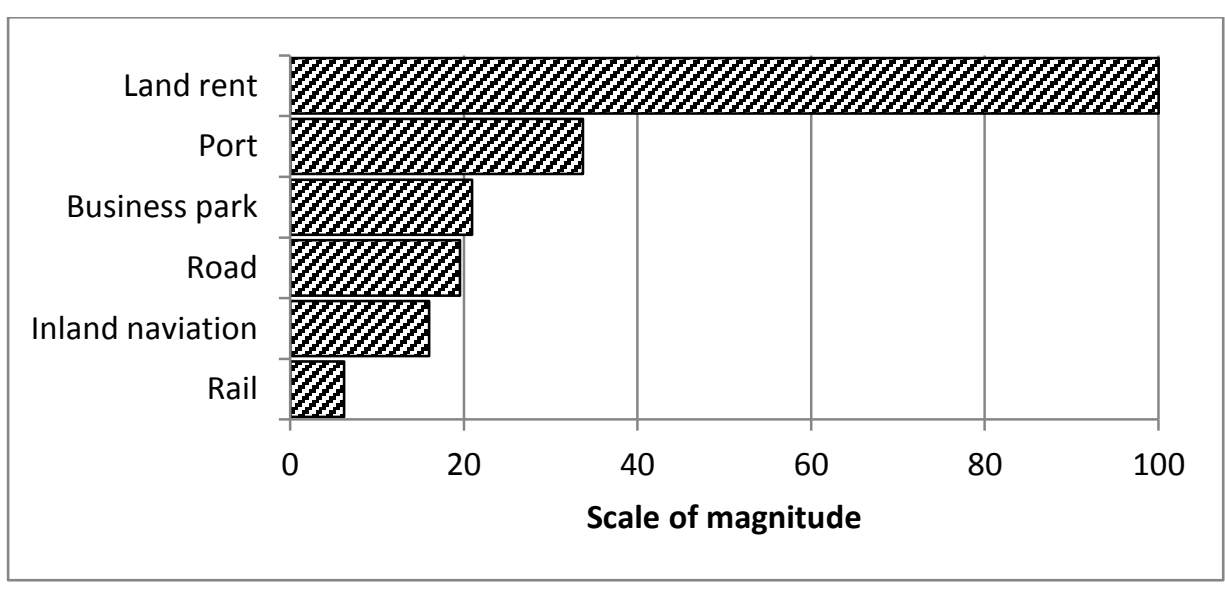

Our study of the most important attribute 'land rent' shows that the utility of a site location decreases linearly with the land rent. The assumption of linearity is supported by the part-worth model (not provided). The considerable standard deviation from this random variable suggests that about 8 of the 100 respondents would value an increase in land rent as positive. This is unexpected and probably the results of the type of distribution assigned. In the final model, we will use an inverse lognormal distribution to prevent positive values. The utility of a site decreases linearly with the distance to a port. For the attribute 'business park', respondents on average assign a positive value to a site that is located in a business park. Our results, based on a normal distribution of the random parameter, suggest that about $78 \%$ of the respondents prefer being situated on a business park over the alternative, while currently $65 \%$ of them is situated in a business park. For the attribute 'road accessibility' we again observe a negative estimate, which indicates that a growing travel time to the main road network is negatively evaluated. The same holds for the distance to inland waterways. However, following the normal distribution of the random variable about 25 out of the 100 respondents assign a positive value to this attribute, which indicates they are indifferent regarding inland navigation. This variation in taste is reflected in the relative low importance of inland navigation. 
To examine the heterogeneity in the preferences of logistic companies in detail, we estimated a MMNL model with covariates. We studied the following four covariates in interaction with the significant location attributes: current transport modes, type of packaging, currently situated in a business park and the company's size. In other words, we estimated models that allow the preferences to vary with the current transport modes used, the type of packaging, being on a business park and the company's size. The included transport modes are 'only road transport' and 'other', so we investigated whether companies that only offer road transport prefer different location characteristics relative to companies that offer other or multimodal transport. We hypothesized that the latter firms pay more attention to the accessibility of a port, an inland navigation terminal and a rail terminal. The levels of the covariate type of packaging are 'only container transport', 'only pallet transport' and 'offering both services'. Because container transport can be considered more internationally oriented, companies that offer container transport may prefer multimodal international gateways relative to pallet transporters who are more road oriented. Finally, the company's size was included, dividing the companies into 'small', 'medium' or 'large' according to their added value. We hypothesized that larger companies are in need of increased accessibility and thus prefer these locations more than smaller firms. The reference category in all cases is the category with the majority of the observations.

The two most important covariates are 'not only road transport' and 'type of packaging' (Table 3). Logistic firms with only road transport are more sensitive to road access and less sensitive to port access. More importantly, they focus on low land rents. Firms that work with pallets also show an above average interest in the proximity to main roads. Firms that only deal with container transport are significantly less interested in the land rent and they are also less sensitive about being on a business park. Firms dealing with both pallets and containers demonstrate a stronger preference for port access and less preference for access to inland waterways. Finally, we observe that companies situated on a business park, prefer to be situated on a business park, while those who currently are not situated on a business park do not care about this, they are more or less indifferent towards this attribute. Firm size also provided two significant interactions, though these are left-out because of correlation with other covariates, lower t-values and a lack of theory. All relevant interactions are included in the final model.

We retained only the relevant attributes and interaction effects to build the final MMNL model. Table 3 shows the marginal utility values of the attributes, their t-values, distribution and LR tests. The main attributes are again presented in decreasing order of importance. Notice that the order of the attributes has changed. The lower relative importance of inland navigation is now more in line with our expectations. Moreover, the number of unexpected estimates decreased. The share of expected negative values for 'port' and 'road' shifted to $93 \%$ and $95 \%$. These numbers correspond more closely to our expectations. The final model with covariates performs better than all previous models, with a log-likelihood below -869 . McFaddens' $\rho^{2}$ for the final model is relatively high, indicating that our model has a high explanatory value. 
1 Table 3: estimates for the attributes and interaction effects for the final MMNL model.

\begin{tabular}{|c|c|c|c|c|c|c|}
\hline Attributes & distr. & estimate & $\mathrm{t}$-value & s.d. & t-value & LR effect $\left(\chi^{2}\right)$ \\
\hline Land rent* & lognormal & -0.0961 & -35.24 & $\mathbf{0 . 0 9 3}$ & 18.46 & 390.1 \\
\hline Road & normal & -0.1731 & -9.54 & 0.107 & 4.64 & 212.2 \\
\hline Port & normal & -0.0586 & -9.78 & 0.041 & 6.96 & 188.1 \\
\hline Business park & normal & 0.3549 & 4.28 & 0.702 & 6.57 & 84.9 \\
\hline Inland navigation & normal & -0.0329 & -3.99 & 0.043 & 4.56 & 38.0 \\
\hline \multicolumn{7}{|c|}{ Covariates - interaction effect } \\
\hline \multirow[t]{3}{*}{ not only road $(n=44)$} & rent & 0.0094 & 3.53 & & & \multirow{9}{*}{59.3} \\
\hline & port & -0.0095 & -2.65 & & & \\
\hline & road & 0.0659 & 4.69 & & & \\
\hline not on a b-park $(n=35)$ & park & -0.2164 & -3.19 & & & \\
\hline pallet transport $(n=39)$ & road & -0.0627 & -4.15 & & & \\
\hline \multirow[t]{2}{*}{ container transport $(n=16)$} & rent & 0.0059 & 2.18 & & & \\
\hline & park & -0.3346 & -4.31 & & & \\
\hline \multirow[t]{2}{*}{ pallet \& container $(n=14)$} & port & -0.0141 & -2.82 & & & \\
\hline & inland & 0.0205 & 2.62 & & & \\
\hline
\end{tabular}

\section{number of coefficients}

final log-likelihood

zero log-likelihood

McFadden $\rho^{2}$ MMNL linear

McFadden $\rho^{2}$ MNL linear

lognormal parameter values, the t-values are based on the original lognormal parameter

A common output of discrete choice studies is the willingness to pay (WTP) for a change from one situation to another. Since we have a final MMNL model with three linear attributes and one attribute with effect coding, it is relatively simple to calculate the WTP for all attributes, by dividing the change in one attribute by our only monetary attribute in this experiment, namely 'land rent'. However, the MMNL model confronts us with a limitation. Both nominator and denominator are random variables with a (log)normal distribution. The results have an unknown variation, standard deviation and mean. With a limited number of observations, in our case 100 respondents, the results are unstable. Therefore, we only present the results based on the median values (Table 4). A more sophisticated approach would be the calculation of the WTP space (Train \& Meeks, 2005). However, this is beyond the scope of this paper. The WTP is based on land rent and therefore expressed in euro's per square meter per year. The WTP values presented reflect the WTP of the reference group of the final model. The results reflect our conclusions above.

Table 4: Willingness to pay per attribute, based on the final MMNL model and median values

\begin{tabular}{lr} 
Change & $\begin{array}{r}\text { WTP } \\
\left(€ / \mathrm{m}^{2} / \mathrm{y}\right)\end{array}$ \\
\hline $1 \mathrm{~km}$ closer to a port & 1.12 \\
1 min closer to main road & 3.29 \\
$1 \mathrm{~km}$ closer to inland waterways & 0.63 \\
to a business park & 13.50
\end{tabular}




\section{Conclusion}

The logistics sector is a major stakeholder in the fragmentation of industrial production processes coming along with globalization. The organization of the spatial networks of logistics companies is one of the most important strategic decisions in this respect that they have to make. The quest for suitable plant locations is crucial in this context. The research described in this paper was carried out in response to the need for new locations for logistics operations. The research, which focused on Flanders (Belgium), is unique in its use of a stated choice experiment in combination with a discrete choice model for identifying the key factors in the search for suitable locations for logistics sites, quantifying their impact on the choices made by logistics managers and determining the Willingness to Pay for improvements in location. The literature on site location in general shows that the accessibility of transport infrastructure and land rent costs are considered the most important location factors for companies. This is even more true when focusing on logistics plants. In the past, traditional questionnaires have been extensively used to study location factors. We break this status quo by adopting a stated choice experimental approach where respondents are forced to choose between different alternative locations.

In the stated choice experiment, all important location factors emerging from the literature review were included. More specifically, the importance of accessibility (in terms of distance to major transport infrastructures) and land rent costs was investigated. The location of a site inside or outside a business park was also incorporated in the stated choice experiment since the Flemish government was very interested in feedback concerning the added value of these subsidized facilities. For the stated choice experiment, we used the distance to a motorway junction, to a sea port, to a rail terminal and to an inland navigation terminal as indicators of accessibility. Our GIS exercise showed that the largest logistics plants in Flanders are predominantly located at short distances of the available transport infrastructure. These distances were used as input to determine the attribute levels utilized in the stated choice experiment. A large share of the respondents of the stated choice study belongs to the group of large logistics plants in Flanders, but SMEs, which are typical for the economy of Flanders, are also included in the pool of respondents. One in four respondents moved location during the last five years or is preparing a move. This demonstrates that location issues are continuously present in the strategic management considerations of logistics companies.

With land rent being by far the most important location factor for logistics sites, the outcome of the stated choice experiment confirms the classical urban economic theories. Our research shows that the access to seaports is the second most important location factor. A seaport is preferably located within 10 kilometers of one's site. Flanders, being served by three major seaports (Antwerpen, Gent, Zeebrugge), therefore offers a substantial number of attractive locations for logistics companies. Furthermore, locations within 5 minutes of a motorway junction and within 15 kilometers from an inland navigation terminal are considered attractive as well. The amenities in business parks, a factor rarely included in location research, are also considered to be very attractive. The distance to a rail terminal, on the other hand, had no significant impact in our study. However, because of recent EU decisions concerning major investments in rail infrastructure and a more efficient management of rail, we would still recommend including rail accessibility in future research.

The results of our stated choice experiment provide valuable input to government agencies that need to identify locations in Flanders suitable for developing new logistics sites. New business parks nearby seaports, well connected by road and within reach of inland shipping terminals would be ideal candidates for further development. Our results indicate a strong preference for locations that lend themselves to intermodal and multimodal transport. This is of crucial importance in densely urbanized 
regions like Flanders and many other seaport areas worldwide, where land for extensive developments is scarce and, consequently, land rents are high. The results of our Willingness to Pay study show that logistics companies are willing to pay a substantially larger annual land rent for attractive locations so that, from a private as well as from a public viewpoint, developments on more expensive, highly accessible locations are preferable to developments on cheap locations with poor accessibility.

\section{Acknowledgements}

The authors are very grateful to the editor, Tim Schwanen, and the reviewers who commented extensively on former versions of the article.

\section{References}

BIRKIN, M., CLARKE, G. P. \& CLARKE, M. 2002. Retail Geography and Intelligent Network Planning, Chichester, John Wiley.

BLIEMER, M. C. J. \& ROSE, J. M. 2010. Construction of experimental designs for mixed logit models allowing for correlation across choice observations. Transportation Research Part BMethodological, 44, 720-734.

BOLIS, S. \& MAGGI, R. 2003. Logistics strategy and transport service choices: An adaptive stated preference experiment. Growth and Change, 34, 490-504.

BCI (BUCK CONSULTANTS INTERNATIONAL) 2007. Logistieke poort Limburg, Zaventem, BCI. BCI (BUCK CONSULTANTS INTERNATIONAL) 2008. Logistieke poort Antwerpen, Zaventem, BCI.

BUS, L. M., VAN HASELEN, H. W. J., VAN DEN BEUKEL, E. \& BÜCKMANN, E. H. 1999. Vervoeren en verankeren: onderzoeken naar doorvoerstromen en logistieke activiteiten, Rotterdam, NEI.

CABUS, P., HOREMANS, E. \& VANHAVERBEKE, W. 2008. Vestigingsgedrag in Vlaanderen, Brussels, Flemish Government.

CBRE 2007. Logistics in Belgium [Online]. Brussels: CBRE. Available: http://www.cbre.eu/be_en/services/logistics_in_belgium [Accessed 12/04/2013].

CROISSANT, Y. 2013. Estimation of multinomial logit models in R : the mlogit packages. Version 0.2-4, Université de la Réunion, Saint-Denis.

CSCMP (COUNCIL OF SUPPLY CHAIN MANAGEMENT PROFESSIONALS) 2014. Supply chain management definitions [Online]. Lombard: CSCMP. Available: http://cscmp.org/about-us/supplychain-management-definitions [Accessed 12/06/2014 2014].

CUSHMAN \& WAKEFIELD 2010. Belgium Industrial Snapshot Q3 2010. London: Cushman \& Wakefield.

CUSHMAN \& WAKEFIELD 2011a. Belgium Industrial Snapshot Q4 2011, London, Cushman \& Wakefield.

CUSHMAN \& WAKEFIELD. 2011b. France Industrial Snapshot Q4 2011, London, Cushman \& Wakefield.

CUSHMAN \& WAKEFIELD 2011c. Germany Industrial Snapshot Q4 2011, London, Cushman \& Wakefield.

CUSHMAN \& WAKEFIELD 2011d. The Netherlands Industrial Snapshot Q4 2011, London, Cushman \& Wakefield.

DEVILLE, X. \& VERDUYN, F. 2012. Implementation of EU legislation on rail liberalization in Belgium, France, Germany and The Netherlands, Brussels, National Bank of Belgium.

EARNHART, D. 2001. Combining revealed and stated preference methods to value environmental amenities at residential locations. Land Economics, 77, 12-29.

EUROPEAN COMMISSION 2014. Statistical pocketbook 2014 Transport, EU Commission, Mobility and Transport.

FLEMISH GOVERNMENT 2012. Flanders in action pact 2020 [Online]. Brussels: Flemish Government. Available: http://www.vlaandereninactie.be [Accessed 09/04/2012]. 
GEURS, K. T. \& WEE, B. V. 2004. Accessibility evaluation of land-use and transport strategies: review and research directions. Journal of Transport Geography, 12, 127-140.

GREEN, P. E. 1974. On the design of choice experiments involving multi-factor alternatives. Journal of Consumer Research, 1, 61-68.

HALL, P., HESSE, M. \& RODRIGUE, J. P. 2006. Reexploring the interface between economic and transport geography. Environment and Planning A, 38, 1401-1408.

HAYASHI, Y., ISOBE, T. \& TOMITA, Y. 1986. Modeling the long-term effects of transport and land-use policies on industrial locational behavior - a discrete choice model system. Regional Science and Urban Economics, 16, 123-143.

HEALEY, M. \& ILBERY, B. 1990. Location \&change. Perspectives on Economic Geography. Oxford, University Press.

HENNINGSEN, A. \& TOOMET, O. 2011. maxLik: A package for maximum likelihood estimation in R. Computational Statistics 26, 443-458.

HENSHER, D. A., BARNARD, P. O. \& TRUONG, T. P. 1988. The role of stated preference methods in studies of travel choice. Journal of Transport Economics and Policy, 22, 45-58.

HENSHER, D. A., ROSE, J. M. \& GREENE, W. H. 2005. Applied choice analysis: a primer, Cambridge, Cambridge University Press.

HESSE, M. 2004. Land for logistics: Locational dynamics, real estate markets and political regulation of regional distribution complexes. Tijdschrift voor Economische en Sociale Geografie, 95, 162-173.

HESSE, M. \& RODRIGUE, J.-P. 2004. The transport geography of logistics and freight distribution. Journal of Transport Geography, 12, 171-184.

HILMOLA, O. P. 2007. European railway freight transportation and adaptation to demand decline: Efficiency and partial productivity analysis from period of 1980-2003. International Journal of Productivity and Performance Management, 56, 205-225.

HOLGUIN-VERAS, J., XU, N., LEVINSON, H., PAASWELL, R., MCKNIGHT, C., WEINER, R., OZBAY, K. \& OZMEN-ERTEKIN, D. 2005. An investigation on the aggregate behavior of firm relocations to New Jersey (1990-1999) and the underlying market elasticities. Networks and Spatial Economics, 5, 293-331.

HONG, J. 2007a. Location determinants and patterns of foreign logistics services in Shanghai, China. The Service Industries Journal, 27, 339-354.

HONG, J. 2007b. Transport and the location of foreign logistics firms: The Chinese experience. Transportation Research Part A: Policy and Practice, 41, 597-609.

HONG, J. J. \& CHIN, A. T. H. 2007. Modeling the location choices of foreign investments in Chinese logistics industry. China Economic Review, 18, 425-437.

HUBER, J. \& ZWERINA, K. 1996. The importance of utility balance in efficient choice designs. Journal of Marketing Research, 33, 307-317.

IDEA CONSULT 2001. Ruimtelijk-economische aspecten van de ontwikkelingen in transport, distributie en logistiek in Vlaanderen, Een onderzoek ter onderbouwing van het locatiebeleid in het kader van het Ruimtelijk Structuurplan Vlaanderen. Brussels, Flemish Government.

IBM 2004. Onderzoek naar de evolutie van de ruimtebehoefte voor niet verweefbare bedrijvigheid, Studie in het kader van de evaluatie van het Ruimtelijk Structuurplan Vlaanderen. Brussels, Flemish Government.

JANSSEN, R. \& URAN, O. 2003. Presentation of information for spatial decision support A survey on the use of maps by participants in quantitative water management in the IJsselmeer region, The Netherlands. Physics and Chemistry of the Earth, Parts A/B/C, 28, 611-620.

JONES LANG LASALLE 2010. Belgium Warehousing Report Spring 2010. Zaventem, Jones Lang LaSalle.

JONES LANG LASALLE 2012a. Belgian Industrial Market Report Autumn 2012. Zaventem, Jones Lang LaSalle.

JONES LANG LASALLE 2012b. Blijven de semi-industriële en de logistieke sector op koers in het huidige economische klimaat? [Online]. Brussels, Jones Lang LaSalle. Available: http://www.joneslanglasalle.be/belgium/nl-nl/Pages/NewsDetail.aspx?ItemID=26241 [Accessed 09/04/2013]. 
JONES LANG LASALLE 2013. Definitieve cijfers van de vastgoed sector voor 2012: de balans [Online]. Brussels, Jones Lang LaSalle. Available: http://www.joneslanglasalle.be/Belgium/NLNL/Pages/NewsDetail.aspx?ItemID=26843 [Accessed 09/04/2013].

KALLAS, S. 2012. Siim Kallas Vice-President and Commissioner for Transport Using freight to help European transport move to a sustainable future. Launch of the Green Freight Europe initiativeBrussels, 27 March 2012 [Online]. Brussels, European Union. Available: http://europa.eu/rapid/press-release_SPEECH-12-230_en.htm [Accessed 16/04/2013].

KESSELS, R., JONES, B. \& GOOS, P. 2011a. Bayesian optimal designs for discrete choice experiments with partial profiles. Journal of Choice Modelling, 4, 52-74.

KESSELS, R., JONES, B. \& GOOS, P. 2012. A comparison of partial profile designs for discrete choice experiments with an application in software development. Research Report No. 2012-004, Faculty of Applied Economics, University of Antwerp, Antwerp, Belgium.

KESSELS, R., JONES, B., GOOS, P. \& VANDEBROEK, M. 2008. Recommendations on the use of Bayesian optimal designs for choice Experiments. Quality and Reliability Engineering International, 24, 737-744.

KESSELS, R., JONES, B., GOOS, P. \& VANDEBROEK, M. 2009. An efficient algorithm for constructing Bayesian optimal choice designs. Journal of Business \& Economic Statistics, 27, 279291.

KESSELS, R., JONES, B., GOOS, P. \& VANDEBROEK, M. 2011b. The usefulness of Bayesian optimal designs for discrete choice experiments. Applied Stochastic Models in Business and Industry, 27, 173-188.

KESSELS, R., JONES, B., GOOS, P. \& VANDEBROEK, M. 2011c. Rejoinder: the usefulness of Bayesian optimal designs for discrete choice experiments. Applied Stochastic Models in Business and Industry, 27, 197-203.

LAGNEAUX, F. 2008. Economic Importance of Belgian Transport Logistics. Brussels, National Bank of Belgium.

LEITHAM, S., MCQUAID, R. W. \& NELSON, J. D. 2000. The influence of transport on industrial location choice: a stated preference experiment. Transportation Research Part A-Policy and Practice, 34, 515-535.

LIM, H. \& THILL, J. C. 2008. Intermodal freight transportation and regional accessibility in the United States. Environment and Planning A, 40, 2006-2025.

LU, C. S. \& YANG, C. C. 2006. Comparison of investment preferences for international logistics zones in Kaohsiung, Hong Kong, and Shanghai ports from a Taiwanese manufacturer's perspective. Transportation Journal, 45, 30-51.

NASH, C. \& RIVERA-TRUJILLO, C. 2007. Rail reform in Europe: Issues and research needs. In: RIETVELD, P. \& STOUGH, R. R. (eds.) Institutions and Sustainable Transport: Regulatory Reform in Advanced Economies. Northampton, Edward Elgar Publishers.

NGUYEN, C. Y. \& SANO, K. 2010. Location choice model for logistic firms with consideration of spatial effects. Transportation Research Board 89th Annual Meeting, Washington D.C.

OZMEN-ERTEKIN, D., OZBAY, K. \& HOLGUIN-VERAS, J. 2007. Role of transportation accessibility in attracting new businesses to New Jersey. Journal of Urban Planning \& Development, 133, 138-149.

R CORE TEAM 2013. R: A language and environment for statistical computing, R Foundation for Statistical Computing, Vienna, Austria. URL http://www.R-project.org/.

REIJS, T., KUIPERS, B. \& CORNELISSEN, C. 2001. Core Centra en vestigingsplaatskeuze, Delft, TNO.

ROSE, J. M. \& BLIEMER, M. C. J. 2009. Constructing efficient stated choice experimental designs. Transport Reviews, 29, 587-617.

SANDOR, Z. \& WEDEL, M. 2005. Heterogeneous conjoint choice designs. Journal of Marketing Research, 42, 210-218.

STEUNPUNT GOEDEREN- EN PERSONENVERVOER 2013. Indicatorenboek 2012 Duurzaam Goederenvervoer Vlaanderen, Antwerpen, Universiteit Antwerpen.

TE BRÖMMELSTROET, M. 2010. Equip the warrior instead of manning the equipment: Land use and transport planning support in the Netherlands. Journal of Transport and Land Use, 3, 25-41. 
TE BRÖMMELSTROET, M. 2012. Transparency, flexibility, simplicity: From buzzwords to strategies for real PSS improvement. Computers, Environment and Urban Systems, 36, 96-104. THILL, J. C. \& LIM, H. 2010. Intermodal containerized shipping in foreign trade and regional accessibility advantages. Journal of Transport Geography, 18, 530-547.

THOMAS, I., HERMIA, J. P., VANELSLANDER, T. \& VERHETSEL, A. 2003. Accessibility to freight transport networks in Belgium: a geographical approach. Tijdschrift voor Economische en Sociale Geografie, 94, 424-438.

THOMAS, I. \& VERHETSEL, A. 1999. Transport routier et mobilité durable: un état de la question pour la Belgique. Hommes et Terre du Nord, 3, 198-203.

TRAIN, K. \& WEEKS, M. 2005. Discrete Choice Models in Preference Space and Willingness-to-Pay Space. In: SCARPA, R. \& ALBERINI, A. (Eds.), Applications of Simulation Methods in Environmental and Resource Economics (pp. 1-16). Springer Netherlands.

TRAIN, K. 2009. Discrete choice methods with simulation, second edition, Cambridge University Press, Cambridge.

URAN, O. \& JANSSEN, R. 2003. Why are spatial decision support systems not used? Some experiences from the Netherlands. Computers, Environment and Urban Systems, 27, 511-526.

VASSALLO, J. M. \& FAGAN, M. 2007. Nature or nurture: why do railroads carry greater freight share in the United States than in Europe? Transportation, 34, 177-193.

VERHETSEL, A., KESSELS, R., BLOMME, N., CANT, J. \& GOOS, P. 2013. Location of logistics companies: a stated preference study to disentangle the impact of accessibility. Research Report No. 2013-024, Faculty of Applied Economics, University of Antwerp, Antwerp, Belgium.

VONK, G., GEERTMAN, S. \& SCHOT, P. 2005. Bottlenecks blocking widespread usage of planning support systems. Environment and Planning A, 37, 909-924.

WILLIGERS, J. \& VAN WEE, B. 2011. High-speed rail and office location choices. A stated choice experiment for the Netherlands. Journal of Transport Geography, 19, 745-754. 


\section{Appendix A: Multivariate normal prior parameter distribution used to construct the Bayesian D-optimal partial profile design for the stated choice experiment.}

This appendix describes the prior distribution used for constructing the Bayesian D-optimal partial profile design for the stated choice experiment. The prior distribution is a 17-variate normal distribution, because the initial modeling approach treated every attribute as categorical. This enables to capture any non-linear effects. As a consequence, the total number of parameters in the initial choice model equals the sum of the numbers of levels of all attributes minus the number of attributes. In this article, we use effect coding for the attribute levels and covariates. Effect coding is a common approach in discrete choice modelling and allows for simple interpretation of the interaction effects. It effects the specification of the prior distribution of the parameters when constructing the design of the stated choice experiment. According to the rules of effect coding the relevant category is coded 1, the reference category is coded -1 , the remaining categories are coded zero. As a result the estimate for the reference category can be calculated as the inverse of the sum of all other estimates of a particular attribute.

To construct the Bayesian D-optimal partial profile design, we used the 17-variate normal prior distribution $N\left(\boldsymbol{\beta} \mid \boldsymbol{\beta}_{0}, \boldsymbol{\Sigma}_{0}\right)$, with prior mean vector and prior variance-covariance matrix. In order to generate experiment designs we used the statistical software package JMP, version 10 (SAS Institute, Cary, NC, USA).

The assumptions regarding the mean values needed to generate an efficient design can be found in Table A1. In our design we assigned the highest importance to the attribute 'land rent'. Least important was 'business park', as we had no prior expectations regarding this attribute. As a result this is the only attribute in the design with a prior mean of zero. The remaining attributes were assigned equal weights and similar prior means.

For the prior variance-covariance matrix $\boldsymbol{\Sigma}_{0}$, we specified 17 variances that express our uncertainty about the prior utility values contained within the prior mean vector $\beta_{0}$. The variances are all equal to 0.09 , because this preserves the natural rank order of the levels of the first five attributes in most cases. This means that the difference between two consecutive prior utility values for each of these attributes is usually larger than or equal to the standard deviation of 0.3 . We also specified negative covariances between the utility values corresponding to a single attribute. If $L_{i}$ denotes the number of levels of attribute $i$, we computed these covariances using a correlation coefficient of $-1 /\left(L_{i}-1\right)$. As explained by Kessels et al. (2008), this ensures that the variances of all prior utility values corresponding to a given attribute are the same, meaning that the variance associated with the implied utility of the last level of each attribute also equals 0.09 . 
2

Prior Relative

Attribute with level mean importance

\begin{tabular}{lrr}
\hline Land rent [10 EUR] & 0.5 & First \\
Land rent [35 EUR] & 0.2 & \\
Land rent [50 EUR] & 0 & \\
Land rent [65 EUR] & -0.2 & \\
Land rent [90 EUR] & -0.5 & \\
\hline Port [0 km] & 0.483 & Second \\
Port [10 km] & 0.167 & \\
Port [20 km] & -0.15 & \\
Port [50 km] & -0.5 & \\
\hline Business park [yes] & 0 & Third \\
Business park [no] & 0 & \\
\hline Road [2 min] & 0.483 & Second \\
Road [5 min] & 0.167 & \\
Road [10 min] & -0.15 & \\
Road [15 min] & -0.5 & \\
\hline Inland nav. [0 km] & 0.483 & Second \\
Inland nav. [5 km] & 0.167 & \\
Inland nav. [15 km] & -0.15 & \\
Inland nav. [30 km] & -0.5 & \\
\hline Rail [0 km] & 0.483 & Second \\
Rail [5 km] & 0.167 & \\
Rail [15 km] & -0.15 & \\
Rail [30 km] & -0.5 & \\
\hline
\end{tabular}

3

4 